\title{
Fuzzy stability of functional inequalities in matrix fuzzy normed spaces
}

Choonkil Park', Dong Yun Shin ${ }^{2 *}$ and Jung Rye Lee ${ }^{3}$

"Correspondence: dyshin@uos.ac.kr

${ }^{2}$ Department of Mathematics,

Daejin University, Kyeonggi,

487-711, Korea

Full list of author information is

available at the end of the article

\begin{abstract}
Using the fixed point method, we prove the Hyers-Ulam stability of additive functional inequalities in matrix fuzzy normed spaces.

MSC: 47L25; 47H10; 46S40; 39B82; 46L07; 39B52; 26E50

Keywords: operator space; fixed point; Hyers-Ulam stability; matrix fuzzy normed space; additive functional inequality; additive functional equation
\end{abstract}

\section{Introduction and preliminaries}

Katsaras [1] defined a fuzzy norm on a vector space to construct a fuzzy vector topological structure on the space. Some mathematicians have defined fuzzy norms on a vector space from various points of view [2-4]. In particular, Bag and Samanta [5], following Cheng and Mordeson [6], gave an idea of a fuzzy norm in such a manner that the corresponding fuzzy metric is of Kramosil and Michalek type [7]. They established a decomposition theorem of a fuzzy norm into a family of crisp norms and investigated some properties of fuzzy normed spaces [8].

We use the definition of fuzzy normed spaces given in $[5,9,10]$ to investigate a fuzzy version of the Hyers-Ulam stability for the Cauchy additive functional inequality and for the Cauchy-Jensen additive functional inequality in the fuzzy normed vector space setting.

Definition 1.1 [5, 9-11] Let $X$ be a real vector space. A function $N: X \times \mathbb{R} \rightarrow[0,1]$ is called a fuzzy norm on $X$ if for all $x, y \in X$ and all $s, t \in \mathbb{R}$,

$\left(\mathrm{N}_{1}\right) \quad N(x, t)=0$ for $t \leq 0$;

$\left(\mathrm{N}_{2}\right) x=0$ if and only if $N(x, t)=1$ for all $t>0$;

$\left(\mathrm{N}_{3}\right) N(c x, t)=N\left(x, \frac{t}{|c|}\right)$ if $c \neq 0$;

$\left(\mathrm{N}_{4}\right) N(x+y, s+t) \geq \min \{N(x, s), N(y, t)\}$;

$\left(\mathrm{N}_{5}\right) N(x, \cdot)$ is a non-decreasing function of $\mathbb{R}$ and $\lim _{t \rightarrow \infty} N(x, t)=1$;

$\left(\mathrm{N}_{6}\right)$ for $x \neq 0, N(x, \cdot)$ is continuous on $\mathbb{R}$.

The pair $(X, N)$ is called a fuzzy normed vector space.

The properties of fuzzy normed vector spaces and examples of fuzzy norms are given in $[10,11]$.

Definition 1.2 [5,9-11] Let $(X, N)$ be a fuzzy normed vector space. A sequence $\left\{x_{n}\right\}$ in $X$ is said to be convergent or converge if there exists an $x \in X$ such that $\lim _{n \rightarrow \infty} N\left(x_{n}-x, t\right)=1$ 
for all $t>0$. In this case, $x$ is called the limit of the sequence $\left\{x_{n}\right\}$ and we denote it by $N-\lim _{n \rightarrow \infty} x_{n}=x$.

Definition $1.3[5,9,10]$ Let $(X, N)$ be a fuzzy normed vector space. A sequence $\left\{x_{n}\right\}$ in $X$ is called Cauchy if for each $\varepsilon>0$ and each $t>0$ there exists an $n_{0} \in \mathbb{N}$ such that for all $n \geq n_{0}$ and all $p>0$, we have $N\left(x_{n+p}-x_{n}, t\right)>1-\varepsilon$.

It is well known that every convergent sequence in a fuzzy normed vector space is Cauchy. If each Cauchy sequence is convergent, then the fuzzy norm is said to be complete and the fuzzy normed vector space is called a fuzzy Banach space.

We say that a mapping $f: X \rightarrow Y$ between fuzzy normed vector spaces $X$ and $Y$ is continuous at a point $x_{0} \in X$ if for each sequence $\left\{x_{n}\right\}$ converging to $x_{0}$ in $X$, the sequence $\left\{f\left(x_{n}\right)\right\}$ converges to $f\left(x_{0}\right)$. If $f: X \rightarrow Y$ is continuous at each $x \in X$, then $f: X \rightarrow Y$ is said to be continuous on $X$ (see [8]).

We will use the following notations:

$M_{n}(X)$ is the set of all $n \times n$-matrices in $X$;

$e_{j} \in M_{1, n}(\mathbb{C})$ is that $j$ th component is 1 and the other components are zero;

$E_{i j} \in M_{n}(\mathbb{C})$ is that $(i, j)$-component is 1 and the other components are zero;

$E_{i j} \otimes x \in M_{n}(X)$ is that $(i, j)$-component is $x$ and the other components are zero.

For $x \in M_{n}(X), y \in M_{k}(X)$,

$$
x \oplus y=\left(\begin{array}{ll}
x & 0 \\
0 & y
\end{array}\right) .
$$

Note that $\left(X,\left\{\|\cdot\|_{n}\right\}\right)$ is a matrix normed space if and only if $\left(M_{n}(X),\|\cdot\|_{n}\right)$ is a normed space for each positive integer $n$ and $\|A x B\|_{k} \leq\|A\|\|B\|\|x\|_{n}$ holds for $A \in M_{k, n}(\mathbb{C}), x=$ $\left(x_{i j}\right) \in M_{n}(X)$ and $B \in M_{n, k}(\mathbb{C})$, and that $\left(X,\left\{\|\cdot\|_{n}\right\}\right)$ is a matrix Banach space if and only if $X$ is a Banach space and $\left(X,\left\{\|\cdot\|_{n}\right\}\right)$ is a matrix normed space.

A matrix normed space $\left(X,\left\{\|\cdot\|_{n}\right\}\right)$ is called an $L^{\infty}$-matrix normed space if $\|x \oplus y\|_{n+k}=$ $\max \left\{\|x\|_{n},\|y\|_{k}\right\}$ holds for all $x \in M_{n}(X)$ and all $y \in M_{k}(X)$.

Let $E, F$ be vector spaces. For a given mapping $h: E \rightarrow F$ and a given positive integer $n$, define $h_{n}: M_{n}(E) \rightarrow M_{n}(F)$ by

$$
h_{n}\left(\left[x_{i j}\right]\right)=\left[h\left(x_{i j}\right)\right]
$$

for all $\left[x_{i j}\right] \in M_{n}(E)$.

We introduce the concept of a matrix fuzzy normed space.

Definition 1.4 Let $(X, N)$ be a fuzzy normed space.

(1) $\left(X,\left\{N_{n}\right\}\right)$ is called a matrix fuzzy normed space if for each positive integer $n$, $\left(M_{n}(X), N_{n}\right)$ is a fuzzy normed space and $N_{k}(A x B, t) \geq N_{n}\left(x, \frac{t}{\|A\| \cdot\|B\|}\right)$ for all $t>0$, $A \in M_{k, n}(\mathbb{R}), x=\left[x_{i j}\right] \in M_{n}(X)$ and $B \in M_{n, k}(\mathbb{R})$ with $\|A\| \cdot\|B\| \neq 0$.

(2) $\left(X,\left\{N_{n}\right\}\right)$ is called a matrix fuzzy Banach space if $(X, N)$ is a fuzzy Banach space and $\left(X,\left\{N_{n}\right\}\right)$ is a matrix fuzzy normed space. 
Example 1.5 Let $\left(X,\left\{\|\cdot\|_{n}\right\}\right)$ be a matrix normed space. Let $N_{n}(x, t):=\frac{t}{t+\|x\|_{n}}$ for all $t>0$ and $x=\left[x_{i j}\right] \in M_{n}(X)$. Then

$$
N_{k}(A x B, t)=\frac{t}{t+\|A x B\|_{k}} \geq \frac{t}{t+\|A\| \cdot\|x\|_{n} \cdot\|B\|}=\frac{\frac{t}{\|A\| \cdot\|B\|}}{\frac{t}{\|A\| \cdot\|B\|}+\|x\|_{n}}
$$

for all $t>0, A \in M_{k, n}(\mathbb{R}), x=\left[x_{i j}\right] \in M_{n}(X)$ and $B \in M_{n, k}(\mathbb{R})$ with $\|A\| \cdot\|B\| \neq 0$. So, $\left(X,\left\{N_{n}\right\}\right)$ is a matrix fuzzy normed space.

The abstract characterization given for linear spaces of bounded Hilbert space operators in terms of matricially normed spaces [12] implies that quotients, mapping spaces, and various tensor products of operator spaces may again be regarded as operator spaces. Owing in part to this result, the theory of operator spaces is having an increasingly significant effect on operator algebra theory (see [13]).

The proof given in [12] appealed to the theory of ordered operator spaces [14]. Effros and Ruan [15] showed that one can give a purely metric proof of this important theorem by using a technique of Pisier [16] and Haagerup [17] (as modified in [18]).

The stability problem of functional equations originated from a question of Ulam [19] concerning the stability of group homomorphisms. Hyers [20] gave the first affirmative partial answer to the question of Ulam for Banach spaces. Hyers' theorem was generalized by Aoki [21] for additive mappings and by Rassias [22] for linear mappings by considering an unbounded Cauchy difference. A generalization of the Rassias theorem was obtained by Găvruta [23] by replacing the unbounded Cauchy difference by a general control function in the spirit of Rassias' approach.

In [24], Gilányi showed that if $f$ satisfies the functional inequality

$$
\left\|2 f(x)+2 f(y)-f\left(x y^{-1}\right)\right\| \leq\|f(x y)\|,
$$

then $f$ satisfies the Jordan-von Neumann functional equation

$$
2 f(x)+2 f(y)=f(x y)+f\left(x y^{-1}\right) .
$$

See also [25]. Gilányi [26] and Fechner [27] proved the Hyers-Ulam stability of the functional inequality (1.1).

Park et al. [28] proved the Hyers-Ulam stability of the following functional inequalities:

$$
\begin{aligned}
& \|f(x)+f(y)+f(z)\| \leq\left\|2 f\left(\frac{x+y+z}{2}\right)\right\|, \\
& \|f(x)+f(y)+f(z)\| \leq\|f(x+y+z)\|, \\
& \|f(x)+f(y)+2 f(z)\| \leq\left\|2 f\left(\frac{x+y}{2}+z\right)\right\| .
\end{aligned}
$$

Let $X$ be a set. A function $d: X \times X \rightarrow[0, \infty]$ is called a generalized metric on $X$ if $d$ satisfies

(1) $d(x, y)=0$ if and only if $x=y$;

(2) $d(x, y)=d(y, x)$ for all $x, y \in X$;

(3) $d(x, z) \leq d(x, y)+d(y, z)$ for all $x, y, z \in X$.

We recall a fundamental result in fixed point theory. 
Theorem 1.6 [29, 30] Let $(X, d)$ be a complete generalized metric space and let $J: X \rightarrow$ $X$ be a strictly contractive mapping with a Lipschitz constant $\alpha<1$. Then, for each given element $x \in X$, either

$$
d\left(J^{n} x, J^{n+1} x\right)=\infty
$$

for all nonnegative integers $n$ or there exists a positive integer $n_{0}$ such that

(1) $d\left(J^{n} x, J^{n+1} x\right)<\infty, \forall n \geq n_{0}$;

(2) the sequence $\left\{J^{n} x\right\}$ converges to a fixed point $y^{*}$ of $J$;

(3) $y^{*}$ is the unique fixed point of $J$ in the set $Y=\left\{y \in X \mid d\left(J^{n_{0}} x, y\right)<\infty\right\}$;

(4) $d\left(y, y^{*}\right) \leq \frac{1}{1-\alpha} d(y, J y)$ for all $y \in Y$.

In 1996, Isac and Rassias [31] were the first to provide applications of stability theory of functional equations for the proof of new fixed point theorems with applications. By using fixed point methods, the stability problems of several functional equations have been extensively investigated by a number of authors (see [32-38]).

Throughout this paper, let $\left(X,\|\cdot\|_{n}\right)$ be a matrix normed space, $\left(Y,\|\cdot\|_{n}\right)$ be a matrix Banach space and let $n$ be a fixed positive integer. Let $\left(X, N_{n}\right)$ be a matrix fuzzy normed space and let $\left(Y, N_{n}\right)$ be a matrix fuzzy Banach space.

In Section 2, we prove the Hyers-Ulam stability of the Cauchy additive functional inequality (1.2) in fuzzy normed spaces by using the fixed point method.

In Section 3, we prove the Hyers-Ulam stability of the Cauchy additive functional equation in matrix fuzzy normed spaces by using the fixed point method.

In Section 4, we prove the Hyers-Ulam stability of the Cauchy-Jensen additive functional inequality (1.3) in fuzzy normed spaces by using the fixed point method.

In Section 5, we prove the Hyers-Ulam stability of the Cauchy additive functional inequality (1.2) in matrix normed spaces by using the direct method and by using the fixed point method.

\section{Hyers-Ulam stability of the Cauchy functional inequality in fuzzy normed spaces}

We need the following lemma to prove the main results.

Lemma 2.1 $[16,39]$ Let $(Y, N)$ be a fuzzy normed vector space. Let $f: X \rightarrow Y$ be a mapping such that

$$
N(f(x)+f(y)+2 f(z), t) \geq N\left(2 f\left(\frac{x+y}{2}+z\right), \frac{2 t}{3}\right)
$$

for all $x, y, z \in X$ and all $t>0$. Then $f$ is Cauchy additive, i.e., $f(x+y)=f(x)+f(y)$ for all $x, y \in X$.

In this section, using the fixed point method, we prove the Hyers-Ulam stability of the Cauchy additive functional inequality (1.2) in fuzzy Banach spaces.

Theorem 2.2 Let $\varphi: X^{3} \rightarrow[0, \infty)$ be a function such that there exists an $L<1$ with

$$
\varphi(x, y, z) \leq \frac{L}{2} \varphi(2 x, 2 y, 2 z)
$$


for all $x, y, z \in X$. Let $f: X \rightarrow Y$ be an odd mapping satisfying

$$
\begin{aligned}
& N(f(x)+f(y)+f(z), t) \\
& \quad \geq \min \left\{N\left(f(x+y+z), \frac{t}{2}\right), \frac{t}{t+\varphi(x, y, z)}\right\}
\end{aligned}
$$

for all $x, y, z \in X$ and all $t>0$. Then $A(x):=N-\lim _{n \rightarrow \infty} 2^{n} f\left(\frac{x}{2^{n}}\right)$ exists for each $x \in X$ and defines an additive mapping $A: X \rightarrow Y$ such that

$$
N(f(x)-A(x), t) \geq \frac{(2-2 L) t}{(2-2 L) t+L \varphi(x, x,-2 x)}
$$

for all $x \in X$ and all $t>0$.

Proof Since $f$ is odd, $f(0)=0$. So, $N\left(f(0), \frac{t}{2}\right)=1$. Letting $y=x$ and replacing $z$ by $-2 x$ in (2.1), we get

$$
N(f(2 x)-2 f(x), t) \geq \frac{t}{t+\varphi(x, x,-2 x)}
$$

for all $x \in X$.

Consider the set

$$
S:=\{g: X \rightarrow Y\}
$$

and introduce the generalized metric on $S$ :

$$
d(g, h)=\inf \left\{\mu \in \mathbb{R}_{+}: N(g(x)-h(x), \mu t) \geq \frac{t}{t+\varphi(x, x,-2 x)}, \forall x \in X, \forall t>0\right\},
$$

where, as usual, $\inf \phi=+\infty$. It is easy to show that $(S, d)$ is complete. (See the proof of [40, Lemma 2.1].)

Now we consider the linear mapping $J: S \rightarrow S$ such that

$$
J g(x):=2 g\left(\frac{x}{2}\right)
$$

for all $x \in X$.

Let $g, h \in S$ be given such that $d(g, h)=\varepsilon$. Then

$$
N(g(x)-h(x), \varepsilon t) \geq \frac{t}{t+\varphi(x, x,-2 x)}
$$

for all $x \in X$ and all $t>0$. Hence

$$
\begin{aligned}
N(J g(x)-J h(x), L \varepsilon t) & =N\left(2 g\left(\frac{x}{2}\right)-2 h\left(\frac{x}{2}\right), L \varepsilon t\right) \\
& =N\left(g\left(\frac{x}{2}\right)-h\left(\frac{x}{2}\right), \frac{L}{2} \varepsilon t\right)
\end{aligned}
$$




$$
\begin{aligned}
& \geq \frac{\frac{L t}{2}}{\frac{L t}{2}+\varphi\left(\frac{x}{2}, \frac{x}{2},-x\right)} \\
& \geq \frac{\frac{L t}{2}}{\frac{L t}{2}+\frac{L}{2} \varphi(x, x,-2 x)} \\
& =\frac{t}{t+\varphi(x, x,-2 x)}
\end{aligned}
$$

for all $x \in X$ and all $t>0$. So, $d(g, h)=\varepsilon$ implies that $d(J g, J h) \leq L \varepsilon$. This means that

$$
d(J g, J h) \leq L d(g, h)
$$

for all $g, h \in S$.

It follows from (2.3) that

$$
N\left(f(x)-2 f\left(\frac{x}{2}\right), \frac{L}{2} t\right) \geq \frac{t}{t+\varphi(x, x,-2 x)}
$$

for all $x \in X$ and all $t>0$. So, $d(f$, , f $) \leq \frac{L}{2}$.

By Theorem 1.6, there exists a mapping $A: X \rightarrow Y$ satisfying the following:

(1) $A$ is a fixed point of $J$, i.e.,

$$
A\left(\frac{x}{2}\right)=\frac{1}{2} A(x)
$$

for all $x \in X$. Since $f: X \rightarrow Y$ is odd, $A: X \rightarrow Y$ is an odd mapping. The mapping $A$ is a unique fixed point of $J$ in the set

$$
M=\{g \in S: d(f, g)<\infty\} .
$$

This implies that $A$ is a unique mapping satisfying (2.4) such that there exists a $\mu \in(0, \infty)$ satisfying

$$
N(f(x)-A(x), \mu t) \geq \frac{t}{t+\varphi(x, x,-2 x)}
$$

for all $x \in X$;

(2) $d\left(J^{n} f, A\right) \rightarrow 0$ as $n \rightarrow \infty$. This implies the equality

$$
N-\lim _{n \rightarrow \infty} 2^{n} f\left(\frac{x}{2^{n}}\right)=A(x)
$$

for all $x \in X$;

(3) $d(f, A) \leq \frac{1}{1-L} d(f, J f)$, which implies the inequality

$$
d(f, A) \leq \frac{L}{2-2 L}
$$

This implies that the inequality (2.2) holds. 
By (2.1),

$$
\begin{aligned}
& N\left(2^{n}\left(f\left(\frac{x}{2^{n}}\right)+f\left(\frac{y}{2^{n}}\right)+f\left(\frac{z}{2^{n}}\right)\right), 2^{n} t\right) \\
& \quad \geq \min \left\{N\left(2^{n} f\left(\frac{x+y+z}{2^{n}}\right), 2^{n-1} t\right), \frac{t}{t+\varphi\left(\frac{x}{2^{n}}, \frac{y}{2^{n}}, \frac{z}{2^{n}}\right)}\right\}
\end{aligned}
$$

for all $x, y, z \in X$, all $t>0$, and all $n \in \mathbb{N}$. So,

$$
\begin{aligned}
& N\left(2^{n}\left(f\left(\frac{x}{2^{n}}\right)+f\left(\frac{y}{2^{n}}\right)+f\left(\frac{z}{2^{n}}\right)\right), t\right) \\
& \quad \geq \min \left\{N\left(2^{n} f\left(\frac{x+y+z}{2^{n}}\right), \frac{t}{2}\right), \frac{\frac{t}{2^{n}}}{\frac{t}{2^{n}}+\frac{L^{n}}{2^{n}} \varphi(x, y, z)}\right\}
\end{aligned}
$$

for all $x, y, z \in X$, all $t>0$, and all $n \in \mathbb{N}$. Since $\lim _{n \rightarrow \infty} \frac{\frac{t}{2^{n}}}{\frac{t}{2^{n}}+\frac{h^{n}}{2^{n}} \varphi(x, y, z)}=1$ for all $x, y, z \in X$ and all $t>0$,

$$
N(A(x)+A(y)+A(z), t) \geq N\left(A(x+y+z), \frac{t}{2}\right)
$$

for all $x, y, z \in X$ and all $t>0$. By [41, Lemma 2.1], the mapping $A: X \rightarrow Y$ is a Cauchy additive, as desired.

Corollary 2.3 Let $\theta \geq 0$ and let $p$ be a real number with $p>1$. Let $X$ be a normed vector space with the norm $\|\cdot\|$. Let $f: X \rightarrow Y$ be an odd mapping satisfying

$$
N(f(x)+f(y)+f(z), t) \geq \min \left\{N\left(f(x+y+z), \frac{t}{2}\right), \frac{t}{t+\theta\left(\|x\|^{p}+\|y\|^{p}+\|z\|^{p}\right)}\right\}
$$

for all $x, y, z \in X$ and all $t>0$. Then $A(x):=N-\lim _{n \rightarrow \infty} 2^{n} f\left(\frac{x}{2^{n}}\right)$ exists for each $x \in X$ and defines an additive mapping $A: X \rightarrow Y$ such that

$$
N(f(x)-A(x), t) \geq \frac{\left(2^{p}-2\right) t}{\left(2^{p}-2\right) t+\left(2+2^{p}\right) \theta\|x\|^{p}}
$$

for all $x \in X$ and all $t>0$.

Proof The proof follows from Theorem 2.2 by taking

$$
\varphi(x, y):=\theta\left(\|x\|^{p}+\|y\|^{p}+\|z\|^{p}\right)
$$

for all $x, y, z \in X$. Then we can choose $L=2^{1-p}$, and we get the desired result.

Theorem 2.4 Let $\varphi: X^{3} \rightarrow[0, \infty)$ be a function such that there exists an $L<1$ with

$$
\varphi(x, y, z) \leq 2 L \varphi\left(\frac{x}{2}, \frac{y}{2}, \frac{z}{2}\right)
$$


for all $x, y, z \in X$. Let $f: X \rightarrow Y$ be an odd mapping satisfying (2.1). Then $A(x):=$ $N$ - $\lim _{n \rightarrow \infty} \frac{1}{2^{n}} f\left(2^{n} x\right)$ exists for each $x \in X$ and defines an additive mapping $A: X \rightarrow Y$ such that

$$
N(f(x)-A(x), t) \geq \frac{(2-2 L) t}{(2-2 L) t+\varphi(x, x,-2 x)}
$$

for all $x \in X$ and all $t>0$.

Proof Let $(S, d)$ be the generalized metric space defined in the proof of Theorem 2.2.

Consider the linear mapping $J: S \rightarrow S$ such that

$$
J g(x):=\frac{1}{2} g(2 x)
$$

for all $x \in X$.

Let $g, h \in S$ be given such that $d(g, h)=\varepsilon$. Then

$$
N(g(x)-h(x), \varepsilon t) \geq \frac{t}{t+\varphi(x, x,-2 x)}
$$

for all $x \in X$ and all $t>0$. Hence

$$
\begin{aligned}
N(J g(x)-J h(x), L \varepsilon t) & =N\left(\frac{1}{2} g(2 x)-\frac{1}{2} h(2 x), L \varepsilon t\right) \\
& =N(g(2 x)-h(2 x), 2 L \varepsilon t) \\
& \geq \frac{2 L t}{2 L t+\varphi(2 x, 2 x,-4 x)} \geq \frac{2 L t}{2 L t+2 L \varphi(x, x,-2 x)} \\
& =\frac{t}{t+\varphi(x, x,-2 x)}
\end{aligned}
$$

for all $x \in X$ and all $t>0$. So, $d(g, h)=\varepsilon$ implies that $d(J g, J h) \leq L \varepsilon$. This means that

$$
d(J g, J h) \leq L d(g, h)
$$

for all $g, h \in S$.

It follows from (2.3) that

$$
N\left(f(x)-\frac{1}{2} f(2 x), \frac{1}{2} t\right) \geq \frac{t}{t+\varphi(x, x,-2 x)}
$$

for all $x \in X$ and all $t>0$. So, $d(f$, , f $) \leq \frac{1}{2}$.

By Theorem 1.6, there exists a mapping $A: X \rightarrow Y$ satisfying the following:

(1) $A$ is a fixed point of $J$, i.e.,

$$
A(2 x)=2 A(x)
$$

for all $x \in X$. Since $f: X \rightarrow Y$ is odd, $A: X \rightarrow Y$ is an odd mapping. The mapping $A$ is a unique fixed point of $J$ in the set

$$
M=\{g \in S: d(f, g)<\infty\} .
$$


This implies that $A$ is a unique mapping satisfying (2.7) such that there exists a $\mu \in(0, \infty)$ satisfying

$$
N(f(x)-A(x), \mu t) \geq \frac{t}{t+\varphi(x, x,-2 x)}
$$

for all $x \in X$;

(2) $d\left(J^{n} f, A\right) \rightarrow 0$ as $n \rightarrow \infty$. This implies the equality

$$
N-\lim _{n \rightarrow \infty} \frac{1}{2^{n}} f\left(2^{n} x\right)=A(x)
$$

for all $x \in X$;

(3) $d(f, A) \leq \frac{1}{1-L} d(f, J f)$, which implies the inequality

$$
d(f, A) \leq \frac{1}{2-2 L} .
$$

This implies that the inequality (2.6) holds.

The rest of the proof is similar to the proof of Theorem 2.2.

Corollary 2.5 Let $\theta \geq 0$ and let $p$ be a real number with $0<p<1$. Let $X$ be a normed vector space with the norm $\|\cdot\|$. Let $f: X \rightarrow Y$ be an odd mapping satisfying (2.5). Then $A(x):=N-\lim _{n \rightarrow \infty} \frac{1}{2^{n}} f\left(2^{n} x\right)$ exists for each $x \in X$ and defines an additive mapping $A: X \rightarrow$ $Y$ such that

$$
N(f(x)-A(x), t) \geq \frac{\left(2-2^{p}\right) t}{\left(2-2^{p}\right) t+\left(2+2^{p}\right) \theta\|x\|^{p}}
$$

for all $x \in X$ and all $t>0$.

Proof The proof follows from Theorem 2.4 by taking

$$
\varphi(x, y):=\theta\left(\|x\|^{p}+\|y\|^{p}+\|z\|^{p}\right)
$$

for all $x, y, z \in X$. Then we can choose $L=2^{p-1}$, and we get the desired result.

\section{Hyers-Ulam stability of the Cauchy additive functional equation in matrix fuzzy normed spaces}

Using a fixed point method, we prove the Hyers-Ulam stability of the Cauchy additive functional equation in matrix fuzzy normed spaces.

We will use the following notations:

$M_{n}(X)$ is the set of all $n \times n$-matrices in $X$;

$e_{j} \in M_{1, n}(\mathbb{R})$ is that $j$ th component is 1 and the other components are zero;

$E_{i j} \in M_{n}(\mathbb{R})$ is that $(i, j)$-component is 1 and the other components are zero;

$E_{i j} \otimes x \in M_{n}(X)$ is that $(i, j)$-component is $x$ and the other components are zero.

Lemma 3.1 Let $\left(X,\left\{N_{n}\right\}\right)$ be a matrix fuzzy normed space.

(1) $N_{n}\left(E_{k l} \otimes x, t\right)=N(x, t)$ for all $t>0$ and $x \in X$. 
(2) For all $\left[x_{i j}\right] \in M_{n}(X)$ and $t=\sum_{i, j=1}^{n} t_{i j}$,

$$
\begin{aligned}
& N\left(x_{k l}, t\right) \geq N_{n}\left(\left[x_{i j}\right], t\right) \geq \min \left\{N\left(x_{i j}, t_{i j}\right): i, j=1,2, \ldots, n\right\}, \\
& N\left(x_{k l}, t\right) \geq N_{n}\left(\left[x_{i j}\right], t\right) \geq \min \left\{N\left(x_{i j}, \frac{t}{n^{2}}\right): i, j=1,2, \ldots, n\right\} .
\end{aligned}
$$

(3) $\lim _{n \rightarrow \infty} x_{n}=x$ if and only if $\lim _{n \rightarrow \infty} x_{i j n}=x_{i j}$ for $x_{n}=\left[x_{i j n}\right], x=\left[x_{i j}\right] \in M_{k}(X)$.

Proof (1) Since $E_{k l} \otimes x=e_{k}^{*} x e_{l}$ and $\left\|e_{k}^{*}\right\|=\left\|e_{l}\right\|=1, N_{n}\left(E_{k l} \otimes x, t\right) \geq N(x, t)$. Since $e_{k}\left(E_{k l} \otimes\right.$ $x) e_{l}^{*}=x, N_{n}\left(E_{k l} \otimes x, t\right) \leq N(x, t)$. So, $N\left(E_{k l} \otimes x, t\right)=N(x, t)$.

(2) $N\left(x_{k l}, t\right)=N\left(e_{k}\left[x_{i j}\right] e_{l}^{*}, t\right) \geq N_{n}\left(\left[x_{i j}\right], \frac{t}{\left\|e_{k}\right\| \cdot\left\|e_{l}\right\|}\right)=N_{n}\left(\left[x_{i j}\right], t\right)$.

$$
\begin{aligned}
N_{n}\left(\left[x_{i j}\right], t\right) & =N_{n}\left(\sum_{i, j=1}^{n} E_{i j} \otimes x_{i j}, t\right) \geq \min \left\{N_{n}\left(E_{i j} \otimes x_{i j}, t_{i j}\right): i, j=1,2, \ldots, n\right\} \\
& =\min \left\{N\left(x_{i j}, t_{i j}\right): i, j=1,2, \ldots, n\right\},
\end{aligned}
$$

where $t=\sum_{i, j=1}^{n} t_{i j}$. So, $N_{n}\left(\left[x_{i j}\right], t\right) \geq \min \left\{N\left(x_{i j}, \frac{t}{n^{2}}\right): i, j=1,2, \ldots, n\right\}$.

(3) By $N\left(x_{k l}, t\right) \geq N_{n}\left(\left[x_{i j}\right], t\right) \geq \min \left\{N\left(x_{i j}, \frac{t}{n^{2}}\right): i, j=1,2, \ldots, n\right\}$, we obtain the result.

For a mapping $f: X \rightarrow Y$, define $D f: X^{2} \rightarrow Y$ and $D f_{n}: M_{n}\left(X^{2}\right) \rightarrow M_{n}(Y)$ by

$$
\begin{aligned}
& D f(a, b)=f(a+b)-f(a)-f(b), \\
& D f_{n}\left(\left[x_{i j}\right],\left[y_{i j}\right]\right):=f_{n}\left(\left[x_{i j}+y_{i j}\right]\right)-f_{n}\left(\left[x_{i j}\right]\right)-f_{n}\left(\left[y_{i j}\right]\right)
\end{aligned}
$$

for all $a, b \in X$ and all $x=\left[x_{i j}\right], y=\left[y_{i j}\right] \in M_{n}(X)$.

Theorem 3.2 Let $\varphi: X^{2} \rightarrow[0, \infty)$ be a function such that there exists an $\alpha<1$ with

$$
\varphi(a, b) \leq \frac{\alpha}{2} \varphi(2 a, 2 b)
$$

for all $a, b \in X$. Let $f: X \rightarrow Y$ be a mapping satisfying

$$
N_{n}\left(D f_{n}\left(\left[x_{i j}\right],\left[y_{i j}\right]\right), t\right) \geq \frac{t}{t+\sum_{i, j=1}^{n} \varphi\left(x_{i j}, y_{i j}\right)}
$$

for all $t>0$ and $x=\left[x_{i j}\right], y=\left[y_{i j}\right] \in M_{n}(X)$. Then $A(a):=N-\lim _{l \rightarrow \infty} 2^{l} f\left(\frac{a}{2^{l}}\right)$ exists for each $a \in X$ and defines an additive mapping $A: X \rightarrow Y$ such that

$$
N\left(f_{n}\left(\left[x_{i j}\right]\right)-A_{n}\left(\left[x_{i j}\right]\right), t\right) \geq \frac{2(1-\alpha) t}{2(1-\alpha) t+n^{2} \alpha \sum_{i, j=1}^{n} \varphi\left(x_{i j}, x_{i j}\right)}
$$

for all $t>0$ and $x=\left[x_{i j}\right] \in M_{n}(X)$.

Proof Let $n=1$. Then (3.2) is equivalent to

$$
N(f(a+b)-f(a)-f(b), t) \geq \frac{t}{t+\varphi(a, b)}
$$

for all $t>0$ and $a, b \in X$. 
Letting $b=a$ in (3.4), we get

$$
N(f(2 a)-2 f(a), t) \geq \frac{t}{t+\varphi(a, a)}
$$

and so

$$
N\left(f(a)-2 f\left(\frac{a}{2}\right), t\right) \geq \frac{t}{t+\varphi\left(\frac{a}{2}, \frac{a}{2}\right)} \geq \frac{t}{t+\frac{\alpha}{2} \varphi(a, a)}
$$

for all $t>0$ and $a \in X$.

Consider the set

$$
S:=\{g: X \rightarrow Y\}
$$

and introduce the generalized metric on $S$ :

$$
d(g, h)=\inf \left\{\mu \in \mathbb{R}_{+}: N(g(a)-h(a), \mu t) \geq \frac{t}{t+\varphi(a, a)}, \forall a \in X, \forall t>0\right\}
$$

where, as usual, $\inf \phi=+\infty$. It is easy to show that $(S, d)$ is complete (see the proof of [ 40 , Lemma 2.1]).

Now we consider the linear mapping $J: S \rightarrow S$ such that

$$
J g(a):=2 g\left(\frac{a}{2}\right)
$$

for all $a \in X$.

Let $g, h \in S$ be given such that $d(g, h)=\varepsilon$. Then

$$
N(g(a)-h(a), \varepsilon t) \geq \frac{t}{t+\varphi(a, a)}
$$

for all $a \in X$ and $t>0$. Hence

$$
\begin{aligned}
N(J g(a)-J h(a), \alpha \varepsilon t) & =N\left(2 g\left(\frac{a}{2}\right)-2 h\left(\frac{a}{2}\right), \alpha \varepsilon t\right) \\
& =N\left(g\left(\frac{a}{2}\right)-h\left(\frac{a}{2}\right), \frac{\alpha}{2} \varepsilon t\right) \\
& \geq \frac{\frac{\alpha t}{2}}{\frac{\alpha t}{2}+\varphi\left(\frac{a}{2}, \frac{a}{2}\right)} \geq \frac{\frac{\alpha t}{2}}{\frac{\alpha t}{2}+\frac{\alpha}{2} \varphi(a, a)}=\frac{t}{t+\varphi(a, a)}
\end{aligned}
$$

for all $a \in X$ and $t>0$. So, $d(g, h)=\varepsilon$ implies that $d(J g, J h) \leq \alpha \varepsilon$. This means that

$$
d(J g, J h) \leq \alpha d(g, h)
$$

for all $g, h \in S$.

It follows from (3.6) that $d(f, J f) \leq \frac{\alpha}{2}$.

By Theorem 1.6, there exists a mapping $A: X \rightarrow Y$ satisfying the following: 
(1) $A$ is a fixed point of $J$, i.e.,

$$
A\left(\frac{a}{2}\right)=\frac{1}{2} A(a)
$$

for all $a \in X$. The mapping $A$ is a unique fixed point of $J$ in the set

$$
M=\{g \in S: d(f, g)<\infty\}
$$

(2) $d\left(J^{l} f, A\right) \rightarrow 0$ as $l \rightarrow \infty$. This implies the equality

$$
N-\lim _{l \rightarrow \infty} 2^{l} f\left(\frac{a}{2^{l}}\right)=A(a)
$$

for all $a \in X$.

(3) $d(f, A) \leq \frac{1}{1-\alpha} d(f, J f)$, which implies the inequality

$$
d(f, A) \leq \frac{\alpha}{2-2 \alpha} .
$$

By (3.4),

$$
N\left(2^{l} f\left(\frac{a+b}{2^{l}}\right)-2^{l} f\left(\frac{a}{2^{l}}\right)-2^{l} f\left(\frac{b}{2^{l}}\right), 2^{l} t\right) \geq \frac{t}{t+\varphi\left(\frac{a}{2^{l}}, \frac{b}{2^{l}}\right)}
$$

for all $a, b \in X$ and $t>0$. So,

$$
N\left(2^{l} f\left(\frac{a+b}{2^{l}}\right)-2^{l} f\left(\frac{a}{2^{l}}\right)-2^{l} f\left(\frac{b}{2^{l}}\right), t\right) \geq \frac{\frac{t}{2^{l}}}{\frac{t}{2^{l}}+\frac{\alpha^{l}}{2^{l}} \varphi(a, b)}
$$

for all $a, b \in X$ and $t>0$. Since $\lim _{l \rightarrow \infty} \frac{\frac{t}{2^{l}}}{\frac{t}{2^{l}}+\frac{\alpha^{l}}{2^{l}} \varphi(a, b)}=1$ for all $a, b \in X$ and $t>0$,

$$
N(A(a+b)-A(a)-A(b), t)=1
$$

for all $a, b \in X$ and $t>0$. Thus $A(a+b)-A(a)-A(b)=0$. So, the mapping $A: X \rightarrow Y$ is additive.

By Lemma 3.1 and (3.7),

$$
\begin{aligned}
N_{n}\left(f_{n}\left(\left[x_{i j}\right]\right)-A_{n}\left(\left[x_{i j}\right]\right), t\right) & \geq \min \left\{N\left(f\left(x_{i j}\right)-A\left(x_{i j}\right), \frac{t}{n^{2}}\right): i, j=1,2, \ldots, n\right\} \\
& \geq \min \left\{\frac{2(1-\alpha) t}{2(1-\alpha) t+n^{2} \alpha \varphi\left(x_{i j}, x_{i j}\right)}: i, j=1,2, \ldots, n\right\} \\
& \geq \frac{2(1-\alpha) t}{2(1-\alpha) t+n^{2} \alpha \sum_{i, j=1}^{n} \varphi\left(x_{i j}, x_{i j}\right)}
\end{aligned}
$$

for all $x=\left[x_{i j}\right] \in M_{n}(X)$. Thus $A: X \rightarrow Y$ is a unique additive mapping satisfying (3.3), as desired. 
Corollary 3.3 Let $r, \theta$ be positive real numbers with $r<1$. Let $f: X \rightarrow Y$ be a mapping satisfying

$$
N_{n}\left(D f_{n}\left(\left[x_{i j}\right],\left[y_{i j}\right]\right), t\right) \geq \frac{t}{t+\sum_{i, j=1}^{n} \theta\left(\left\|x_{i j}\right\|^{r}+\left\|y_{i j}\right\|^{r}\right)}
$$

for all $t>0$ and $x=\left[x_{i j}\right], y=\left[y_{i j}\right] \in M_{n}(X)$. Then $A(a):=N-\lim _{l \rightarrow \infty} 2^{l} f\left(\frac{a}{2^{l}}\right)$ exists for each $a \in X$ and defines an additive mapping $A: X \rightarrow Y$ such that

$$
N\left(f_{n}\left(\left[x_{i j}\right]\right)-A_{n}\left(\left[x_{i j}\right]\right), t\right) \geq \frac{\left(2-2^{r}\right) t}{\left(2-2^{r}\right) t+n^{2} \cdot 2^{r} \sum_{i, j=1}^{n} \theta\left\|x_{i j}\right\|^{r}}
$$

for all $t>0$ and $x=\left[x_{i j}\right] \in M_{n}(X)$.

Proof The proof follows from Theorem 3.2 by taking $\varphi(a, b)=\theta\left(\|a\|^{r}+\|b\|^{r}\right)$ for all $a, b \in X$. Then we can choose $\alpha=2^{r-1}$, and we get the desired result.

Theorem 3.4 Let $f: X \rightarrow Y$ be a mapping satisfying (3.2) for which there exists a function $\varphi: X^{2} \rightarrow[0, \infty)$ such that there exists an $\alpha<1$ with

$$
\varphi(a, b) \leq 2 \alpha \varphi\left(\frac{a}{2}, \frac{b}{2}\right)
$$

for all $a, b \in X$. Then $A(a):=N-\lim _{l \rightarrow \infty} \frac{1}{2} f\left(2^{l} a\right)$ exists for each $a \in X$ and defines an additive mapping $A: X \rightarrow Y$ such that

$$
N\left(f_{n}\left(\left[x_{i j}\right]\right)-A_{n}\left(\left[x_{i j}\right]\right), t\right) \geq \frac{2(1-\alpha) t}{2(1-\alpha) t+n^{2} \sum_{i, j=1}^{n} \varphi\left(x_{i j}, x_{i j}\right)}
$$

for all $t>0$ and $x=\left[x_{i j}\right] \in M_{n}(X)$.

Proof Let $(S, d)$ be the generalized metric space defined in the proof of Theorem 3.2.

Now we consider the linear mapping $J: S \rightarrow S$ such that

$$
J g(a):=2 g\left(\frac{a}{2}\right)
$$

for all $a \in X$.

It follows from (3.5) that $d(f, J f) \leq \frac{1}{2}$. So,

$$
d(f, A) \leq \frac{1}{2-2 \alpha} .
$$

The rest of the proof is similar to the proof of Theorem 3.2.

Corollary 3.5 Let $r, \theta$ be positive real numbers with $r>1$. Let $f: X \rightarrow Y$ be a mapping satisfying (3.8). Then $A(a):=N-\lim _{l \rightarrow \infty} 2^{l} f\left(\frac{a}{2^{l}}\right)$ exists for each $a \in X$ and defines an additive 
mapping $A: X \rightarrow Y$ such that

$$
N\left(f_{n}\left(\left[x_{i j}\right]\right)-A_{n}\left(\left[x_{i j}\right]\right), t\right) \geq \frac{\left(2^{r}-2\right) t}{\left(2^{r}-2\right) t+n^{2} \cdot 2^{r} \sum_{i, j=1}^{n} \theta\left\|x_{i j}\right\|^{r}}
$$

for all $t>0$ and $x=\left[x_{i j}\right] \in M_{n}(X)$.

Proof The proof follows from Theorem 3.4 by taking $\varphi(a, b)=\theta\left(\|a\|^{r}+\|b\|^{r}\right)$ for all $a, b \in X$. Then we can choose $\alpha=2^{1-r}$, and we get the desired result.

\section{Fuzzy stability of the Cauchy-Jensen additive functional inequality (1.3) in fuzzy normed spaces}

In this section, using the fixed point method, we prove the generalized Hyers-Ulam stability of the Cauchy-Jensen additive functional inequality (1.3) in fuzzy Banach spaces.

Theorem 4.1 Let $\varphi: X^{3} \rightarrow[0, \infty)$ be a function such that there exists an $L<1$ with

$$
\varphi(x, y, z) \leq \frac{L}{2} \varphi(2 x, 2 y, 2 z)
$$

for all $x, y, z \in X$. Let $f: X \rightarrow Y$ be an odd mapping satisfying

$$
N(f(x)+f(y)+f(2 z), t) \geq \min \left\{N\left(2 f\left(\frac{x+y}{2}+z\right), \frac{2 t}{3}\right), \frac{t}{t+\varphi(x, y, z)}\right\}
$$

for all $x, y, z \in X$ and all $t>0$. Then $A(x):=N-\lim _{n \rightarrow \infty} 2^{n} f\left(\frac{x}{2^{n}}\right)$ exists for each $x \in X$ and defines an additive mapping $A: X \rightarrow Y$ such that

$$
N(f(x)-A(x), t) \geq \frac{(2-2 L) t}{(2-2 L) t+L \varphi(x, x,-x)}
$$

for all $x \in X$ and all $t>0$.

Proof Letting $y=x=-z$ in (4.1), we get

$$
N(f(2 x)-2 f(x), t) \geq \frac{t}{t+\varphi(x, x,-x)}
$$

for all $x \in X$.

Consider the set

$$
S:=\{g: X \rightarrow Y\}
$$

and introduce the generalized metric on $S$ :

$$
d(g, h)=\inf \left\{\mu \in \mathbb{R}_{+}: N(g(x)-h(x), \mu t) \geq \frac{t}{t+\varphi(x, x,-x)}, \forall x \in X, \forall t>0\right\},
$$

where, as usual, $\inf \phi=+\infty$. It is easy to show that $(S, d)$ is complete. (See the proof of [40, Lemma 2.1].) 
Now we consider the linear mapping $J: S \rightarrow S$ such that

$$
J g(x):=2 g\left(\frac{x}{2}\right)
$$

for all $x \in X$.

Let $g, h \in S$ be given such that $d(g, h)=\varepsilon$. Then

$$
N(g(x)-h(x), \varepsilon t) \geq \frac{t}{t+\varphi(x, x,-x)}
$$

for all $x \in X$ and all $t>0$. Hence

$$
\begin{aligned}
N(g(x)-J h(x), L \varepsilon t) & =N\left(2 g\left(\frac{x}{2}\right)-2 h\left(\frac{x}{2}\right), L \varepsilon t\right) \\
& =N\left(g\left(\frac{x}{2}\right)-h\left(\frac{x}{2}\right), \frac{L}{2} \varepsilon t\right) \\
& \geq \frac{\frac{L t}{2}}{\frac{L t}{2}+\varphi\left(\frac{x}{2}, \frac{x}{2},-\frac{x}{2}\right)} \geq \frac{\frac{L t}{2}}{\frac{L t}{2}+\frac{L}{2} \varphi(x, x,-x)} \\
& =\frac{t}{t+\varphi(x, x,-x)}
\end{aligned}
$$

for all $x \in X$ and all $t>0$. So, $d(g, h)=\varepsilon$ implies that $d(J g, J h) \leq L \varepsilon$. This means that

$$
d(J g, J h) \leq L d(g, h)
$$

for all $g, h \in S$.

It follows from (4.3) that

$$
N\left(f(x)-2 f\left(\frac{x}{2}\right), \frac{L}{2} t\right) \geq \frac{t}{t+\varphi(x, x,-x)}
$$

for all $x \in X$ and all $t>0$. So, $d(f$, ,f $) \leq \frac{L}{2}$.

By Theorem 1.6, there exists a mapping $A: X \rightarrow Y$ satisfying the following:

(1) $A$ is a fixed point of $J$, i.e.,

$$
A\left(\frac{x}{2}\right)=\frac{1}{2} A(x)
$$

for all $x \in X$. Since $f: X \rightarrow Y$ is odd, $A: X \rightarrow Y$ is an odd mapping. The mapping $A$ is a unique fixed point of $J$ in the set

$$
M=\{g \in S: d(f, g)<\infty\} .
$$

This implies that $A$ is a unique mapping satisfying (4.4) such that there exists a $\mu \in(0, \infty)$ satisfying

$$
N(f(x)-A(x), \mu t) \geq \frac{t}{t+\varphi(x, x,-x)}
$$

for all $x \in X$; 
(2) $d\left(J^{n} f, A\right) \rightarrow 0$ as $n \rightarrow \infty$. This implies the equality

$$
N-\lim _{n \rightarrow \infty} 2^{n} f\left(\frac{x}{2^{n}}\right)=A(x)
$$

for all $x \in X$;

(3) $d(f, A) \leq \frac{1}{1-L} d(f, J f)$, which implies the inequality

$$
d(f, A) \leq \frac{L}{2-2 L}
$$

This implies that the inequality (4.2) holds.

The rest of proof is similar to the proof of Theorem 2.2.

Corollary 4.2 Let $\theta \geq 0$ and let $p$ be a real number with $p>1$. Let $X$ be a normed vector space with the norm $\|\cdot\|$. Let $f: X \rightarrow Y$ be an odd mapping satisfying

$$
\begin{aligned}
& N(f(x)+f(y)+f(2 z), t) \\
& \quad \geq \min \left\{N\left(f\left(\frac{x+y}{2}+z\right), \frac{2 t}{3}\right), \frac{t}{t+\theta\left(\|x\|^{p}+\|y\|^{p}+\|z\|^{p}\right)}\right\}
\end{aligned}
$$

for all $x, y, z \in X$ and all $t>0$. Then $A(x):=N-\lim _{n \rightarrow \infty} 2^{n} f\left(\frac{x}{2^{n}}\right)$ exists for each $x \in X$ and defines an additive mapping $A: X \rightarrow Y$ such that

$$
N(f(x)-A(x), t) \geq \frac{\left(2^{p}-2\right) t}{\left(2^{p}-2\right) t+3 \theta\|x\|^{p}}
$$

for all $x \in X$ and all $t>0$.

Proof The proof follows from Theorem 4.1 by taking

$$
\varphi(x, y):=\theta\left(\|x\|^{p}+\|y\|^{p}+\|z\|^{p}\right)
$$

for all $x, y, z \in X$. Then we can choose $L=2^{1-p}$, and we get the desired result.

Theorem 4.3 Let $\varphi: X^{3} \rightarrow[0, \infty)$ be a function such that there exists an $L<1$ with

$$
\varphi(x, y, z) \leq 2 L \varphi\left(\frac{x}{2}, \frac{y}{2}, \frac{z}{2}\right)
$$

for all $x, y, z \in X$. Let $f: X \rightarrow Y$ be an odd mapping satisfying (4.1). Then $A(x):=$ $N$ - $\lim _{n \rightarrow \infty} \frac{1}{2^{n}} f\left(2^{n} x\right)$ exists for each $x \in X$ and defines an additive mapping $A: X \rightarrow Y$ such that

$$
N(f(x)-A(x), t) \geq \frac{(2-2 L) t}{(2-2 L) t+\varphi(x, x,-x)}
$$

for all $x \in X$ and all $t>0$. 
Proof Let $(S, d)$ be the generalized metric space defined in the proof of Theorem 4.1.

Consider the linear mapping $J: S \rightarrow S$ such that

$$
J g(x):=\frac{1}{2} g(2 x)
$$

for all $x \in X$.

Let $g, h \in S$ be given such that $d(g, h)=\varepsilon$. Then

$$
N(g(x)-h(x), \varepsilon t) \geq \frac{t}{t+\varphi(x, x,-x)}
$$

for all $x \in X$ and all $t>0$. Hence

$$
\begin{aligned}
N(J g(x)-J h(x), L \varepsilon t) & =N\left(\frac{1}{2} g(2 x)-\frac{1}{2} h(2 x), L \varepsilon t\right) \\
& =N(g(2 x)-h(2 x), 2 L \varepsilon t) \\
& \geq \frac{2 L t}{2 L t+\varphi(2 x, 2 x,-2 x)} \geq \frac{2 L t}{2 L t+2 L \varphi(x, x,-x)} \\
& =\frac{t}{t+\varphi(x, x,-x)}
\end{aligned}
$$

for all $x \in X$ and all $t>0$. So, $d(g, h)=\varepsilon$ implies that $d(J g, J h) \leq L \varepsilon$. This means that

$$
d(J g, J h) \leq L d(g, h)
$$

for all $g, h \in S$.

It follows from (4.3) that

$$
N\left(f(x)-\frac{1}{2} f(2 x), \frac{1}{2} t\right) \geq \frac{t}{t+\varphi(x, x,-x)}
$$

for all $x \in X$ and all $t>0$. So, $d(f$, ,f $) \leq \frac{1}{2}$.

By Theorem 1.6, there exists a mapping $A: X \rightarrow Y$ satisfying the following:

(1) $A$ is a fixed point of $J$, i.e.,

$$
A(2 x)=2 A(x)
$$

for all $x \in X$. Since $f: X \rightarrow Y$ is odd, $A: X \rightarrow Y$ is an odd mapping. The mapping $A$ is a unique fixed point of $J$ in the set

$$
M=\{g \in S: d(f, g)<\infty\}
$$

This implies that $A$ is a unique mapping satisfying (4.7) such that there exists a $\mu \in(0, \infty)$ satisfying

$$
N(f(x)-A(x), \mu t) \geq \frac{t}{t+\varphi(x, x,-x)}
$$

for all $x \in X$; 
(2) $d\left(J^{n} f, A\right) \rightarrow 0$ as $n \rightarrow \infty$. This implies the equality

$$
N-\lim _{n \rightarrow \infty} \frac{1}{2^{n}} f\left(2^{n} x\right)=A(x)
$$

for all $x \in X$;

(3) $d(f, A) \leq \frac{1}{1-L} d(f, J f)$, which implies the inequality

$$
d(f, A) \leq \frac{1}{2-2 L}
$$

This implies that the inequality (4.6) holds.

The rest of the proof is similar to the proof of Theorem 2.2.

Corollary 4.4 Let $\theta \geq 0$ and let $p$ be a real number with $0<p<1$. Let $X$ be a normed vector space with the norm $\|\cdot\|$. Let $f: X \rightarrow Y$ be an odd mapping satisfying (4.5). Then $A(x):=N-\lim _{n \rightarrow \infty} \frac{1}{2^{n}} f\left(2^{n} x\right)$ exists for each $x \in X$ and defines an additive mapping $A: X \rightarrow$ $Y$ such that

$$
N(f(x)-A(x), t) \geq \frac{\left(2-2^{p}\right) t}{\left(2-2^{p}\right) t+3 \theta\|x\|^{p}}
$$

for all $x \in X$ and all $t>0$.

Proof The proof follows from Theorem 4.3 by taking

$$
\varphi(x, y):=\theta\left(\|x\|^{p}+\|y\|^{p}+\|z\|^{p}\right)
$$

for all $x, y, z \in X$. Then we can choose $L=2^{p-1}$, and we get the desired result.

\section{Hyers-Ulam stability of the additive functional inequality (1.2) in matrix normed spaces}

In this section, we prove the Hyers-Ulam stability of the additive functional inequality (1.2) in matrix normed spaces by using the direct method and by using the fixed point method.

Lemma 5.1 Let $\left(X,\left\{\|\cdot\|_{n}\right\}\right)$ be a matrix normed space.

(1) $\left\|E_{k l} \otimes x\right\|_{n}=\|x\|$ for $x \in X$;

(2) $\left\|x_{k l}\right\| \leq\left\|\left[x_{i j}\right]\right\|_{n} \leq \sum_{i, j=1}^{n}\left\|x_{i j}\right\|$ for $\left[x_{i j}\right] \in M_{n}(X)$;

(3) $\lim _{n \rightarrow \infty} x_{n}=x$ if and only if $\lim _{n \rightarrow \infty} x_{n i j}=x_{i j}$ for $x_{n}=\left[x_{n i j}\right], x=\left[x_{i j}\right] \in M_{k}(X)$.

Proof (1) Since $E_{k l} \otimes x=e_{k}^{*} x e_{l}$ and $\left\|e_{k}^{*}\right\|=\left\|e_{l}\right\|=1,\left\|E_{k l} \otimes x\right\|_{n} \leq\|x\|$. Since $e_{k}\left(E_{k l} \otimes x\right) e_{l}^{*}=x$, $\|x\| \leq\left\|E_{k l} \otimes x\right\|_{n}$. So, $\left\|E_{k l} \otimes x\right\|_{n}=\|x\|$.

(2) Since $e_{k} x e_{l}^{*}=x_{k l}$ and $\left\|e_{k}\right\|=\left\|e_{l}^{*}\right\|=1,\left\|x_{k l}\right\| \leq\left\|\left[x_{i j}\right]\right\|_{n}$.

Since $\left[x_{i j}\right]=\sum_{i, j=1}^{n} E_{i j} \otimes x_{i j}$,

$$
\left\|\left[x_{i j}\right]\right\|_{n}=\left\|\sum_{i, j=1}^{n} E_{i j} \otimes x_{i j}\right\|_{n} \leq \sum_{i, j=1}^{n}\left\|E_{i j} \otimes x_{i j}\right\|_{n}=\sum_{i, j=1}^{n}\left\|x_{i j}\right\| .
$$


(3) By (2), we have

$$
\left\|x_{n k l}-x_{k l}\right\| \leq\left\|\left[x_{n i j}-x_{i j}\right]\right\|_{n}=\left\|\left[x_{n i j}\right]-\left[x_{i j}\right]\right\|_{n} \leq \sum_{i, j=1}^{n}\left\|x_{n i j}-x_{i j}\right\| .
$$

So, we get the result.

We need the following result.

Lemma 5.2 [28, Proposition 2.2] Let $f: X \rightarrow Y$ be a mapping such that

$$
\|f(a)+f(b)+f(c)\| \leq\|f(a+b+c)\|
$$

for all $a, b, c \in X$. Then $f: X \rightarrow Y$ is additive.

Theorem 5.3 Let $f: X \rightarrow Y$ be a mapping and let $\phi: X^{3} \rightarrow[0, \infty)$ be a function such that

$$
\begin{aligned}
& \Phi(a, b, c):=\frac{1}{2} \sum_{l=0}^{\infty} \frac{1}{2^{l}} \phi\left(2^{l} a, 2^{l} b, 2^{l} c\right)<+\infty, \\
& \left\|f_{n}\left(\left[x_{i j}\right]\right)+f_{n}\left(\left[y_{i j}\right]\right)+f_{n}\left(\left[z_{i j}\right]\right)\right\|_{n} \\
& \quad \leq\left\|f_{n}\left(\left[x_{i j}\right]+\left[y_{i j}\right]+\left[z_{i j}\right]\right)\right\|_{n}+\sum_{i, j=1}^{n} \phi\left(x_{i j}, y_{i j}, z_{i j}\right)
\end{aligned}
$$

for all $a, b, c \in X$ and all $x=\left[x_{i j}\right], y=\left[y_{i j}\right], z=\left[z_{i j}\right] \in M_{n}(X)$. Then there exists a unique additive mapping $A: X \rightarrow Y$ such that

$$
\left\|f_{n}\left(\left[x_{i j}\right]\right)-A_{n}\left(\left[x_{i j}\right]\right)\right\|_{n} \leq \sum_{i, j=1}^{n} \Phi\left(x_{i j}, x_{i j},-2 x_{i j}\right)
$$

for all $x=\left[x_{i j}\right] \in M_{n}(X)$.

Proof When $n=1,(5.2)$ is equivalent to

$$
\|f(a)+f(b)+f(c)\| \leq\|f(a+b+c)\|+\phi(a, b, c)
$$

for all $a, b, c \in X$. By the same reasoning as in the proof of [28, Theorem 3.2], one can show that there is a unique additive mapping $A: X \rightarrow Y$ such that

$$
\|f(a)-A(a)\| \leq \Phi(a, a,-2 a)
$$

for all $a \in X$. The mapping $A: X \rightarrow Y$ is given by

$$
A(a)=\lim _{l \rightarrow \infty} \frac{1}{2^{l}} f\left(2^{l} a\right)
$$


for all $a \in X$. By Lemma 5.1,

$$
\left\|f_{n}\left(\left[x_{i j}\right]\right)-A_{n}\left(\left[x_{i j}\right]\right)\right\|_{n} \leq \sum_{i, j=1}^{n}\left\|f\left(x_{i j}\right)-A\left(x_{i j}\right)\right\| \leq \sum_{i, j=1}^{n} \Phi\left(x_{i j}, x_{i j},-2 x_{i j}\right)
$$

for all $x=\left[x_{i j}\right] \in M_{n}(X)$. Thus $A: X \rightarrow Y$ is a unique additive mapping satisfying (5.3), as desired.

Corollary 5.4 Let $r, \theta$ be positive real numbers with $r<1$. Let $f: X \rightarrow Y$ be a mapping such that

$$
\begin{aligned}
\left\|f_{n}\left(\left[x_{i j}\right]\right)+f_{n}\left(\left[y_{i j}\right]\right)+f_{n}\left(\left[z_{i j}\right]\right)\right\|_{n} \leq & \left\|f_{n}\left(\left[x_{i j}\right]+\left[y_{i j}\right]+\left[z_{i j}\right]\right)\right\|_{n} \\
& +\sum_{i, j=1}^{n} \theta\left(\left\|x_{i j}\right\|^{r}+\left\|y_{i j}\right\|^{r}+\left\|z_{i j}\right\|^{r}\right)
\end{aligned}
$$

for all $x=\left[x_{i j}\right], y=\left[y_{i j}\right], z=\left[z_{i j}\right] \in M_{n}(X)$. Then there exists a unique additive mapping $A$ : $X \rightarrow Y$ such that

$$
\left\|f_{n}\left(\left[x_{i j}\right]\right)-A_{n}\left(\left[x_{i j}\right]\right)\right\|_{n} \leq \sum_{i, j=1}^{n} \frac{2+2^{r}}{2-2^{r}} \theta\left\|x_{i j}\right\|^{r}
$$

for all $x=\left[x_{i j}\right] \in M_{n}(X)$.

Proof Letting $\phi(a, b, c)=\theta\left(\|a\|^{r}+\|b\|^{r}+\|c\|^{r}\right)$ in Theorem 5.3, we obtain the result.

Theorem 5.5 Let $f: X \rightarrow Y$ be a mapping and let $\phi: X^{3} \rightarrow[0, \infty)$ be a function satisfying (5.2) and

$$
\Phi(a, b, c):=\frac{1}{2} \sum_{l=1}^{\infty} 2^{l} \phi\left(\frac{a}{2^{l}}, \frac{b}{2^{l}}, \frac{c}{2^{l}}\right)<+\infty
$$

for all $a, b, c \in X$. Then there exists a unique additive mapping $A: X \rightarrow Y$ such that

$$
\left\|f_{n}\left(\left[x_{i j}\right]\right)-A_{n}\left(\left[x_{i j}\right]\right)\right\|_{n} \leq \sum_{i, j=1}^{n} \Phi\left(x_{i j}, x_{i j},-2 x_{i j}\right)
$$

for all $x=\left[x_{i j}\right] \in M_{n}(X)$.

Proof The proof is similar to the proof of Theorem 5.3.

Corollary 5.6 Let $r, \theta$ be positive real numbers with $r>1$. Let $f: X \rightarrow Y$ be a mapping satisfying (5.4). Then there exists a unique additive mapping $A: X \rightarrow Y$ such that

$$
\left\|f_{n}\left(\left[x_{i j}\right]\right)-A_{n}\left(\left[x_{i j}\right]\right)\right\|_{n} \leq \sum_{i, j=1}^{n} \frac{2^{r}+2}{2^{r}-2} \theta\left\|x_{i j}\right\|^{r}
$$

for all $x=\left[x_{i j}\right] \in M_{n}(X)$. 
Proof Letting $\phi(a, b, c)=\theta\left(\|a\|^{r}+\|b\|^{r}+\|c\|^{r}\right)$ in Theorem 5.5, we obtain the result.

We need the following result.

Lemma 5.7 [42] IfE is an $L^{\infty}$-matrix normed space, then $\left\|\left[x_{i j}\right]\right\|_{n} \leq\left\|\left[\left\|x_{i j}\right\|\right]\right\|_{n}$ for all $\left[x_{i j}\right] \in$ $M_{n}(E)$.

Theorem 5.8 Let $Y$ be an $L^{\infty}$-normed Banach space. Let $f: X \rightarrow Y$ be a mapping and let $\phi: X^{3} \rightarrow[0, \infty)$ be a function satisfying (5.1) and

$$
\left\|f_{n}\left(\left[x_{i j}\right]\right)+f_{n}\left(\left[y_{i j}\right]\right)+f_{n}\left(\left[z_{i j}\right]\right)\right\|_{n} \leq\left\|f_{n}\left(\left[x_{i j}\right]+\left[y_{i j}\right]+\left[z_{i j}\right]\right)\right\|_{n}+\left\|\left[\phi\left(x_{i j}, y_{i j}, z_{i j}\right)\right]\right\|_{n}
$$

for all $x=\left[x_{i j}\right], y=\left[y_{i j}\right], z=\left[z_{i j}\right] \in M_{n}(X)$. Then there exists a unique additive mapping $A$ : $X \rightarrow Y$ such that

$$
\left\|\left[f\left(x_{i j}\right)-A\left(x_{i j}\right)\right]\right\|_{n} \leq\left\|\left[\Phi\left(x_{i j}, x_{i j},-2 x_{i j}\right)\right]\right\|_{n}
$$

for all $x=\left[x_{i j}\right] \in M_{n}(X)$. Here $\Phi$ is given in Theorem 5.3.

Proof By the same reasoning as in the proof of Theorem 5.3, there exists a unique additive mapping $A: X \rightarrow Y$ such that

$$
\|f(a)-A(a)\| \leq \Phi(a, a,-2 a)
$$

for all $a \in X$. The mapping $A: X \rightarrow Y$ is given by

$$
A(a)=\lim _{l \rightarrow \infty} \frac{1}{2^{l}} f\left(2^{l} a\right)
$$

for all $a \in X$.

It is easy to show that if $0 \leq a_{i j} \leq b_{i j}$ for all $i, j$, then

$$
\left\|\left[a_{i j}\right]\right\|_{n} \leq\left\|\left[b_{i j}\right]\right\|_{n}
$$

By Lemma 5.7 and (5.8),

$$
\left\|\left[f\left(x_{i j}\right)-A\left(x_{i j}\right)\right]\right\|_{n} \leq\left\|\left[\left\|f\left(x_{i j}\right)-A\left(x_{i j}\right)\right\|\right]\right\|_{n} \leq\left\|\left[\Phi\left(x_{i j}, x_{i j},-2 x_{i j}\right)\right]\right\|_{n}
$$

for all $x=\left[x_{i j}\right] \in M_{n}(X)$. So, we obtain the inequality (5.7).

Corollary 5.9 Let $Y$ be an $L^{\infty}$-normed Banach space. Let $r, \theta$ be positive real numbers with $r<1$. Let $f: X \rightarrow Y$ be a mapping such that

$$
\begin{aligned}
\left\|f_{n}\left(\left[x_{i j}\right]\right)+f_{n}\left(\left[y_{i j}\right]\right)+f_{n}\left(\left[z_{i j}\right]\right)\right\|_{n} \leq & \left\|f_{n}\left(\left[x_{i j}\right]+\left[y_{i j}\right]+\left[z_{i j}\right]\right)\right\|_{n} \\
& +\left\|\left[\theta\left(\left\|x_{i j}\right\|^{r}+\left\|y_{i j}\right\|^{r}+\left\|z_{i j}\right\|^{r}\right)\right]\right\|_{n}
\end{aligned}
$$


for all $x=\left[x_{i j}\right], y=\left[y_{i j}\right], z=\left[z_{i j}\right] \in M_{n}(X)$. Then there exists a unique additive mapping $A$ : $X \rightarrow Y$ such that

$$
\left\|f_{n}\left(\left[x_{i j}\right]\right)-A_{n}\left(\left[x_{i j}\right]\right)\right\|_{n} \leq\left\|\left[\frac{2-2^{r}}{2-2^{r}} \theta\left\|x_{i j}\right\|^{r}\right]\right\|_{n}
$$

for all $x=\left[x_{i j}\right] \in M_{n}(X)$.

Proof Letting $\phi(a, b, c)=\theta\left(\|a\|^{r}+\|b\|^{r}+\|c\|^{r}\right)$ in Theorem 5.8, we obtain the result.

Theorem 5.10 Let $Y$ be an $L^{\infty}$-normed Banach space. Let $f: X \rightarrow Y$ be a mapping and let $\phi: X^{3} \rightarrow[0, \infty)$ be a function satisfying (5.5) and (5.6). Then there exists a unique additive mapping $A: X \rightarrow Y$ such that

$$
\left\|\left[f\left(x_{i j}\right)-A\left(x_{i j}\right)\right]\right\|_{n} \leq\left\|\left[\Phi\left(x_{i j}, x_{i j},-2 x_{i j}\right)\right]\right\|_{n}
$$

for all $x=\left[x_{i j}\right] \in M_{n}(X)$. Here $\Phi$ is given in Theorem 5.5 .

Proof The proof is similar to the proof of Theorem 5.8.

Corollary 5.11 Let $Y$ be an $L^{\infty}$-normed Banach space. Let $r, \theta$ be positive real numbers with $r>1$. Let $f: X \rightarrow Y$ be a mapping satisfying (5.9). Then there exists a unique additive mapping $A: X \rightarrow Y$ such that

$$
\left\|f_{n}\left(\left[x_{i j}\right]\right)-A_{n}\left(\left[x_{i j}\right]\right)\right\|_{n} \leq\left\|\left[\frac{2^{r}+2}{2^{r}-2} \theta\left\|x_{i j}\right\|^{r}\right]\right\|_{n}
$$

for all $x=\left[x_{i j}\right] \in M_{n}(X)$.

Proof Letting $\phi(a, b, c)=\theta\left(\|a\|^{r}+\|b\|^{r}+\|c\|^{r}\right)$ in Theorem 5.10, we obtain the result.

Theorem 5.12 Let $\phi: X^{3} \rightarrow[0, \infty)$ be a function such that there exists an $\alpha<1$ with

$$
\phi(a, b, c) \leq 2 \alpha \phi\left(\frac{a}{2}, \frac{b}{2}, \frac{c}{2}\right)
$$

for all $a, b, c \in X$. Let $f: X \rightarrow Y$ be a mapping satisfying (5.2). Then there exists a unique additive mapping $A: X \rightarrow Y$ such that

$$
\left\|f_{n}\left(\left[x_{i j}\right]\right)-A_{n}\left(\left[x_{i j}\right]\right)\right\|_{n} \leq \sum_{i, j=1}^{n} \frac{1}{2-2 \alpha} \phi\left(x_{i j}, x_{i j},-2 x_{i j}\right)
$$

for all $x=\left[x_{i j}\right] \in M_{n}(X)$.

Proof When $n=1,(5.2)$ is equivalent to

$$
\|f(a)+f(b)+f(c)\| \leq\|f(a+b+c)\|+\phi(a, b, c)
$$


for all $a, b, c \in X$. It follows from (5.12) that

$$
\|2 f(a)-f(2 a)\| \leq \phi(a, a,-2 a)
$$

for all $a \in X$. So,

$$
\left\|f(a)-\frac{1}{2} f(2 a)\right\| \leq \frac{1}{2} \phi(a, a,-2 a)
$$

for all $a \in X$.

Consider the set

$$
S:=\{h: X \rightarrow Y\}
$$

and introduce the generalized metric on $S$ :

$$
d(g, h)=\inf \left\{\mu \in \mathbb{R}_{+}:\|g(a)-h(a)\| \leq \mu \phi(a, a,-2 a), \forall a \in X\right\}
$$

where, as usual, $\inf \{\}=+\infty$. It is easy to show that $(S, d)$ is complete (see [40]).

Now we consider the linear mapping $J: S \rightarrow S$ such that

$$
J g(a):=\frac{1}{2} g(2 a)
$$

for all $a \in X$.

Let $g, h \in S$ be given such that $d(g, h)=\varepsilon$. Then

$$
\|g(a)-h(a)\| \leq \phi(a, a,-2 a)
$$

for all $a \in X$. Hence

$$
\|J g(a)-J h(a)\|=\left\|\frac{1}{2} g(2 a)-\frac{1}{2} h(2 a)\right\| \leq \alpha \phi(a, a,-2 a)
$$

for all $a \in X$. So, $d(g, h)=\varepsilon$ implies that $d(J g, J h) \leq \alpha \varepsilon$. This means that

$$
d(J g, J h) \leq \alpha d(g, h)
$$

for all $g, h \in S$.

It follows from (5.14) that $d(f, J f) \leq \frac{1}{2}$.

By Theorem 1.6, there exists a mapping $A: X \rightarrow Y$ satisfying the following:

(1) $A$ is a fixed point of $J$, i.e.,

$$
A(2 a)=2 A(x)
$$

for all $x \in X$. The mapping $A$ is a unique fixed point of $J$ in the set

$$
M=\{g \in S: d(h, g)<\infty\} .
$$


This implies that $A$ is a unique mapping satisfying (5.15) such that there exists a $\mu \in(0, \infty)$ satisfying

$$
\|f(a)-A(a)\| \leq \mu \phi(a, a,-2 a)
$$

for all $a \in X$;

(2) $d\left(J^{l} f, A\right) \rightarrow 0$ as $l \rightarrow \infty$. This implies the equality

$$
\lim _{l \rightarrow \infty} \frac{1}{2^{l}} f\left(2^{l} a\right)=A(a)
$$

for all $a \in X$;

(3) $d(f, A) \leq \frac{1}{1-\alpha} d(f, J f)$, which implies the inequality

$$
d(f, A) \leq \frac{1}{2-2 \alpha} .
$$

So,

$$
\|f(a)-A(a)\| \leq \frac{1}{2-2 \alpha} \phi(a, a,-2 a)
$$

for all $a \in X$.

It follows from (5.10) and (5.12) that

$$
\begin{aligned}
& \lim _{l \rightarrow \infty} \frac{1}{2^{l}}\left\|f\left(2^{l} a\right)+f\left(2^{l} b\right)+f\left(2^{l} c\right)\right\| \\
& \quad \leq \lim _{l \rightarrow \infty}\left(\frac{1}{2^{l}}\left\|f\left(2^{l}(a+b+c)\right)\right\|+\frac{1}{2^{l}} \phi\left(2^{l} a, 2^{l} b, 2^{l} c\right)\right)
\end{aligned}
$$

for all $a, b, c \in X$.

It follows from (5.17) that

$$
\|A(a)+A(b)+A(c)\| \leq\|A(a+b+c)\|
$$

for all $a, b, c \in X$. By Lemma 5.2, $A: X \rightarrow Y$ is additive.

By Lemma 5.7 and (5.16),

$$
\left\|f_{n}\left(\left[x_{i j}\right]\right)-A_{n}\left(\left[x_{i j}\right]\right)\right\|_{n} \leq \sum_{i, j=1}^{n}\left\|f\left(x_{i j}\right)-A\left(x_{i j}\right)\right\| \leq \sum_{i, j=1}^{n} \frac{1}{2-2 \alpha} \phi\left(x_{i j}, x_{i j},-2 x_{i j}\right)
$$

for all $x=\left[x_{i j}\right] \in M_{n}(X)$. Thus $A: X \rightarrow Y$ is a unique additive mapping satisfying (5.11), as desired.

Corollary 5.13 Let $r, \theta$ be positive real numbers with $r<1$. Let $f: X \rightarrow Y$ be a mapping satisfying (5.9). Then there exists a unique additive mapping $A: X \rightarrow Y$ such that

$$
\left\|f_{n}\left(\left[x_{i j}\right]\right)-A_{n}\left(\left[x_{i j}\right]\right)\right\|_{n} \leq \sum_{i, j=1}^{n} \frac{2+2^{r}}{2-2^{r}} \theta\left\|x_{i j}\right\|^{r}
$$

for all $x=\left[x_{i j}\right] \in M_{n}(X)$. 
Proof The proof follows from Theorem 5.12 by taking $\phi(a, b, c)=\theta\left(\|a\|^{r}+\|b\|^{r}+\|c\|^{r}\right)$ for all $a, b, c \in X$. Then we can choose $\alpha=2^{r-1}$, and we get the desired result.

Theorem 5.14 Let $f: X \rightarrow Y$ be a mapping satisfying (5.2) for which there exists a function $\phi: X^{3} \rightarrow[0, \infty)$ such that there exists an $\alpha<1$ with

$$
\phi(a, b, c) \leq \frac{\alpha}{2} \phi(2 a, 2 b, 2 c)
$$

for all $a, b, c \in X$. Then there exists a unique additive mapping $A: X \rightarrow Y$ such that

$$
\left\|f_{n}\left(\left[x_{i j}\right]\right)-A_{n}\left(\left[x_{i j}\right]\right)\right\|_{n} \leq \sum_{i, j=1}^{n} \frac{\alpha}{2-2 \alpha} \phi\left(x_{i j}, x_{i j},-2 x_{i j}\right)
$$

for all $x=\left[x_{i j}\right] \in M_{n}(X)$.

Proof Let $(S, d)$ be the generalized metric space defined in the proof of Theorem 5.12.

Now we consider the linear mapping $J: S \rightarrow S$ such that

$$
J g(a):=2 g\left(\frac{a}{2}\right)
$$

for all $a \in X$.

It follows from (5.13) that

$$
\left\|f(a)-2 f\left(\frac{a}{2}\right)\right\| \leq \phi\left(\frac{a}{2}, \frac{a}{2},-a\right) \leq \frac{\alpha}{2} \phi(a, a,-2 a)
$$

for all $a \in X$. Thus $d(f, J f) \leq \frac{\alpha}{2}$. So,

$$
d(f, A) \leq \frac{\alpha}{2-2 \alpha}
$$

The rest of the proof is similar to the proof of Theorem 5.12.

Corollary 5.15 Let $r, \theta$ be positive real numbers with $r>1$. Let $f: X \rightarrow Y$ be a mapping satisfying (5.9). Then there exists a unique additive mapping $A: X \rightarrow Y$ such that

$$
\left\|f_{n}\left(\left[x_{i j}\right]\right)-A_{n}\left(\left[x_{i j}\right]\right)\right\|_{n} \leq \sum_{i, j=1}^{n} \frac{2^{r}+2}{2^{r}-2} \theta\left\|x_{i j}\right\|^{r}
$$

for all $x=\left[x_{i j}\right] \in M_{n}(X)$.

Proof The proof follows from Theorem 5.14 by taking $\phi(a, b, c)=\theta\left(\|a\|^{r}+\|b\|^{r}+\|c\|^{r}\right)$ for all $a, b, c \in X$. Then we can choose $\alpha=2^{1-r}$, and we get the desired result.

From now on, assume that $Y$ is an $L^{\infty}$-normed Banach space. 
Theorem 5.16 Letf $: X \rightarrow Y$ be a mapping and let $\phi: X^{3} \rightarrow[0, \infty)$ be a function satisfying (5.10) and (5.6). Then there exists a unique additive mapping $A: X \rightarrow Y$ such that

$$
\left\|\left[f\left(x_{i j}\right)-A\left(x_{i j}\right)\right]\right\|_{n} \leq\left\|\left[\frac{1}{2-2 \alpha} \phi\left(x_{i j}, x_{i j},-2 x_{i j}\right)\right]\right\|_{n}
$$

for all $x=\left[x_{i j}\right] \in M_{n}(X)$.

Proof By the same reasoning as in the proof of Theorem 5.12, there exists a unique additive mapping $A: X \rightarrow Y$ such that

$$
\|f(a)-A(a)\| \leq \frac{1}{2-2 \alpha} \phi(a, a,-2 a)
$$

for all $a \in X$.

By Lemma 5.7 and (5.8),

$$
\left\|\left[f\left(x_{i j}\right)-A\left(x_{i j}\right)\right]\right\|_{n} \leq\left\|\left[\left\|f\left(x_{i j}\right)-A\left(x_{i j}\right)\right\|\right]\right\|_{n} \leq\left\|\left[\frac{1}{2-2 \alpha} \phi\left(x_{i j}, x_{i j}\right)\right]\right\|_{n}
$$

for all $x=\left[x_{i j}\right] \in M_{n}(X)$. So, we obtain the inequality (5.19).

Corollary 5.17 Let $r, \theta$ be positive real numbers with $r<1$. Let $f: X \rightarrow Y$ be a mapping satisfying (5.9). Then there exists a unique additive mapping $A: X \rightarrow Y$ such that

$$
\left\|f_{n}\left(\left[x_{i j}\right]\right)-A_{n}\left(\left[x_{i j}\right]\right)\right\|_{n} \leq\left\|\left[\frac{2-2^{r}}{2-2^{r}} \theta\left\|x_{i j}\right\|^{r}\right]\right\|_{n}
$$

for all $x=\left[x_{i j}\right] \in M_{n}(X)$.

Proof The proof follows from Theorem 5.16 by taking $\phi(a, b, c)=\theta\left(\|a\|^{r}+\|b\|^{r}+\|c\|^{r}\right)$ for all $a, b, c \in X$. Then we can choose $\alpha=2^{r-1}$, and we get the desired result.

Theorem 5.18 Let $f: X \rightarrow Y$ be a mapping and let $\phi: X^{3} \rightarrow[0, \infty)$ be a function satisfying (5.6) and (5.18). Then there exists a unique additive mapping $A: X \rightarrow Y$ such that

$$
\left\|\left[f\left(x_{i j}\right)-A\left(x_{i j}\right)\right]\right\|_{n} \leq\left\|\left[\frac{\alpha}{2-2 \alpha} \phi\left(x_{i j}, x_{i j},-2 x_{i j}\right)\right]\right\|_{n}
$$

for all $x=\left[x_{i j}\right] \in M_{n}(X)$.

Proof The proof is similar to the proof of Theorem 5.16.

Corollary 5.19 Let $r, \theta$ be positive real numbers with $r>1$. Let $f: X \rightarrow Y$ be a mapping satisfying (5.9). Then there exists a unique additive mapping $A: X \rightarrow Y$ such that

$$
\left\|f_{n}\left(\left[x_{i j}\right]\right)-A_{n}\left(\left[x_{i j}\right]\right)\right\|_{n} \leq\left\|\left[\frac{2^{2}+2}{2^{r}-2} \theta\left\|x_{i j}\right\|^{r}\right]\right\|_{n}
$$

for all $x=\left[x_{i j}\right] \in M_{n}(X)$. 
Proof The proof follows from Theorem 5.18 by taking $\phi(a, b, c)=\theta\left(\|a\|^{r}+\|b\|^{r}+\|c\|^{r}\right)$ for all $a, b, c \in X$. Then we can choose $\alpha=2^{1-r}$, and we get the desired result.

\section{Competing interests}

The authors declare that they have no competing interests.

\section{Authors' contributions}

All authors conceived of the study, participated in its design and coordination, drafted the manuscript, participated in the sequence alignment, and read and approved the final manuscript.

\section{Author details}

'Department of Mathematics, Research Institute for Natural Sciences, Hanyang University, Seoul, 133-791, Korea.

${ }^{2}$ Department of Mathematics, Daejin University, Kyeonggi, 487-711, Korea. ${ }^{3}$ Department of Mathematics, University of Seoul, Seoul, 130-743, Korea.

\section{Acknowledgements}

CP was supported by the Basic Science Research Program through the National Research Foundation of Korea funded by the Ministry of Education, Science and Technology (NRF-2012R1A1A2004299) and DYS was supported by the Basic Science Research Program through the National Research Foundation of Korea funded by the Ministry of Education, Science and Technology (NRF-2010-0021792)

Received: 26 October 2012 Accepted: 22 April 2013 Published: 6 May 2013

\section{References}

1. Katsaras, AK: Fuzzy topological vector spaces II. Fuzzy Sets Syst. 12, 143-154 (1984)

2. Felbin, C: Finite dimensional fuzzy normed linear spaces. Fuzzy Sets Syst. 48, 239-248 (1992)

3. Krishna, SV, Sarma, KKM: Separation of fuzzy normed linear spaces. Fuzzy Sets Syst. 63, $207-217$ (1994)

4. Xiao, JZ, Zhu, XH: Fuzzy normed spaces of operators and its completeness. Fuzzy Sets Syst. 133, $389-399$ (2003)

5. Bag, T, Samanta, SK: Finite dimensional fuzzy normed linear spaces. J. Fuzzy Math. 11, 687-705 (2003)

6. Cheng, SC, Mordeson, JM: Fuzzy linear operators and fuzzy normed linear spaces. Bull. Calcutta Math. Soc. 86 429-436 (1994)

7. Kramosil, I, Michalek, J: Fuzzy metric and statistical metric spaces. Kybernetika 11, 326-334 (1975)

8. Bag, T, Samanta, SK: Fuzzy bounded linear operators. Fuzzy Sets Syst. 151, 513-547 (2005)

9. Mirmostafaee, AK, Moslehian, MS: Fuzzy versions of Hyers-Ulam-Rassias theorem. Fuzzy Sets Syst. 159, 720-729 (2008)

10. Mirmostafaee, AK, Mirzavaziri, M, Moslehian, MS: Fuzzy stability of the Jensen functional equation. Fuzzy Sets Syst. $159,730-738(2008)$

11. Mirmostafaee, AK, Moslehian, MS: Fuzzy approximately cubic mappings. Inf. Sci. 178, 3791-3798 (2008)

12. Ruan, ZJ: Subspaces of $C^{*}$-algebras. J. Funct. Anal. 76, 217-230 (1988)

13. Effros, E, Ruan, ZJ: On approximation properties for operator spaces. Int. J. Math. 1, 163-187 (1990)

14. Choi, MD Effros, E: Injectivity and operator spaces. J. Funct. Anal. 24, 156-209 (1977)

15. Effros, E, Ruan, ZJ: On the abstract characterization of operator spaces. Proc. Am. Math. Soc. 119, $579-584$ (1993)

16. Pisier, G: Grothendieck's theorem for non-commutative $C^{*}$-algebras with an appendix on Grothendieck's constants. J. Funct. Anal. 29, 397-415 (1978)

17. Haagerup, U: Decomp. of completely bounded maps. Preprint

18. Effros, E: On multilinear completely bounded module maps. In: Operator Algebras and Mathematical Physics (lowa City, lowa, 1985). Contemp. Math., vol. 62, pp. 479-501. Am. Math. Soc., Providence (1987)

19. Ulam, SM: A Collection of the Mathematical Problems. Interscience, New York (1960)

20. Hyers, DH: On the stability of the linear functional equation. Proc. Natl. Acad. Sci. USA 27, $222-224$ (1941)

21. Aoki, T: On the stability of the linear transformation in Banach spaces. J. Math. Soc. Jpn. 2, 64-66 (1950)

22. Rassias, TM: On the stability of the linear mapping in Banach spaces. Proc. Am. Math. Soc. 72, 297-300 (1978)

23. Găvruta, P: A generalization of the Hyers-Ulam-Rassias stability of approximately additive mappings. J. Math. Anal. Appl. 184, 431-436 (1994)

24. Gilányi, A: Eine zur Parallelogrammgleichung äquivalente Ungleichung. Aequ. Math. 62, 303-309 (2001)

25. Rätz, J: On inequalities associated with the Jordan-von Neumann functional equation. Aequ. Math. 66, 191-200 (2003)

26. Gilányi, A: On a problem by K. Nikodem. Math. Inequal. Appl. 5, 707-710 (2002)

27. Fechner, W: Stability of a functional inequalities associated with the Jordan-von Neumann functional equation. Aequ. Math. 71, 149-161 (2006)

28. Park, C, Cho, Y, Han, M: Functional inequalities associated with Jordan-von Neumann type additive functional equations. J. Inequal. Appl. 2007, Article ID 41820 (2007)

29. Cădariu, L, Radu, V: Fixed points and the stability of Jensen's functional equation. J. Inequal. Pure Appl. Math. 4(1), Article ID 4 (2003)

30. Diaz, J, Margolis, B: A fixed point theorem of the alternative for contractions on a generalized complete metric space. Bull. Am. Math. Soc. 74, 305-309 (1968)

31. Isac, G, Rassias, TM: Stability of $\psi$-additive mappings: applications to nonlinear analysis. Int. J. Math. Math. Sci. 19 219-228 (1996)

32. Cădariu, L, Radu, V: On the stability of the Cauchy functional equation: a fixed point approach. Grazer Math. Ber. 346 , 43-52 (2004) 
33. Cădariu, L, Radu, V: Fixed point methods for the generalized stability of functional equations in a single variable. Fixed Point Theory Appl. 2008, Article ID 749392 (2008)

34. Jung, Y, Chang, I: The stability of a cubic type functional equation with the fixed point alternative. J. Math. Anal. Appl. 306, 752-760 (2005)

35. Mirzavaziri, M, Moslehian, MS: A fixed point approach to stability of a quadratic equation. Bull. Braz. Math. Soc. 37, 361-376 (2006)

36. Park, C: Fixed points and Hyers-Ulam-Rassias stability of Cauchy-Jensen functional equations in Banach algebras. Fixed Point Theory Appl. 2007, Article ID 50175 (2007)

37. Park, C: Generalized Hyers-Ulam-Rassias stability of quadratic functional equations: a fixed point approach. Fixed Point Theory Appl. 2008, Article ID 493751 (2008)

38. Radu, V: The fixed point alternative and the stability of functional equations. Fixed Point Theory Appl. 4, 91-96 (2003)

39. Cho, Y, Park, C, Saadati, R: Fuzzy functional inequalities. J. Comput. Anal. Appl. 13, 305-320 (2011)

40. Miheț, D, Radu, V: On the stability of the additive Cauchy functional equation in random normed spaces. J. Math. Anal. Appl. 343, 567-572 (2008)

41. Park, C: Fixed points and stability of the Cauchy-Jensen functional inequality in fuzzy Banach algebras. Appl. Math. Lett. 24, 2024-2029 (2011)

42. Shin, D, Lee, S, Byun, C, Kim, S: On matrix normed spaces. Bull. Korean Math. Soc. 27, 103-112 (1983)

doi:10.1186/1029-242X-2013-224

Cite this article as: Park et al.: Fuzzy stability of functional inequalities in matrix fuzzy normed spaces. Journal of Inequalities and Applications 2013 2013:224.

\section{Submit your manuscript to a SpringerOpen ${ }^{\ominus}$ journal and benefit from:}

- Convenient online submission

- Rigorous peer review

- Immediate publication on acceptance

- Open access: articles freely available online

- High visibility within the field

- Retaining the copyright to your article 